\title{
Revitalizing the ethanologenic bacterium Zymomonas mobilis for sugar reduction in high-sugar-content fruits and commercial products
}

\author{
Mimi Hu${ }^{1 \dagger}$, Xiangyu Chen ${ }^{1 \dagger}$, Ju Huang ${ }^{1}$, Jun Du², Mian Li $i^{3}$ and Shihui Yang ${ }^{1 *}$ (D)
}

\begin{abstract}
The excessive consumption of sugars can cause health issues. Different strategies have been developed to reduce sugars in the diets. However, sugars in fruits and commercial products may be difficult to reduce, limiting their usage among certain populations of people. Zymomonas mobilis is a generally recognized as safe (GRAS) probiotic bacterium with the capability to produce levan-type prebiotics, and thrives in high-sugar environments with unique characteristics to be developed for lignocellulosic biofuel and biochemical production. In this study, the sugar reduction capabilities of Z. mobilis ZM4 were examined using two fruits of pear and persimmon and three high-sugar-content commercial products of two pear pastes (PPs) and one Chinese traditional wine (CTW). Our results demonstrated that Z. mobilis ZM4 can utilize sugars in fruits with about $20 \mathrm{~g} / \mathrm{L}$ ethanol and less than $5 \mathrm{~g} / \mathrm{L}$ sorbitol produced within $22 \mathrm{~h}$ using pears, and about $45 \mathrm{~g} / \mathrm{L}$ ethanol and $30 \mathrm{~g} / \mathrm{L}$ sorbitol produced within $34 \mathrm{~h}$ using persimmons. When PPs made from pears were used, Z. mobilis can utilize nearly all glucose (ca. $60 \mathrm{~g} / \mathrm{L})$ and most fructose $(110 \mathrm{~g} / \mathrm{L})$ within $100 \mathrm{~h}$ with $40 \sim 60 \mathrm{~g} / \mathrm{L}$ ethanol and more than $20 \mathrm{~g} / \mathrm{L}$ sorbitol produced resulting in a final sorbitol concentration above $80 \mathrm{~g} / \mathrm{L}$. In the high-sugar-content alcoholic Chinese traditional wine, which contains mostly glucose and ethanol, Z. mobilis can reduce nearly all sugars with about $30 \mathrm{~g} / \mathrm{L}$ ethanol produced, resulting in a final ethanol above $90 \mathrm{~g} / \mathrm{L}$. The ethanol yield and percentage yield of Z. mobilis in $50 \sim 60 \%$ CTW were $0.44 \sim 0.50 \mathrm{~g} / \mathrm{g}$ and $86 \sim 97 \%$, respectively, which are close to its theoretical yields - especially in $60 \%$ CTW. Although the ethanol yield and percentage yield in PPs were lower than those in CTW, they were similar to those in fruits of pears and persimmons with an ethanol yield around $0.30 \sim 0.37 \mathrm{~g} / \mathrm{g}$ and ethanol percentage yield around $60 \sim 72 \%$, which could be due to the formation of sorbitol and/ or levan in the presence of both glucose and fructose. Our study also compared the fermentation performance of the classical ethanologenic yeast Saccharomyces cerevisiae BY4743 to Z. mobilis, with results suggesting that Z. mobilis ZM4 had better performance than that of yeast S. cerevisiae BY4743 given a higher sugar conversion rate and ethanol yield for sugar reduction. This work thus laid a foundation for utilizing the advantages of Z. mobilis in the food industry to reduce sugar concentrations or potentially produce alcoholic prebiotic beverages.
\end{abstract}

Keywords: Zymomonas mobilis, Saccharomyces cerevisiae, Fruits, Chinese wine, Fermentation, Sugar reduction

\footnotetext{
*Correspondence: Shihui.Yang@hubu.edu.cn

${ }^{\dagger}$ Mimi Hu and Xiangyu Chen contributed equally to this work

${ }^{1}$ State Key Laboratory of Biocatalysis and Enzyme Engineering, Environmental Microbial Technology Center of Hubei Province, and School of Life Sciences, Hubei University, Wuhan 430062, China Full list of author information is available at the end of the article
}

(c) The Author(s) 2021. Open Access This article is licensed under a Creative Commons Attribution 4.0 International License, which permits use, sharing, adaptation, distribution and reproduction in any medium or format, as long as you give appropriate credit to the original author(s) and the source, provide a link to the Creative Commons licence, and indicate if changes were made. The images or other third party material in this article are included in the article's Creative Commons licence, unless indicated otherwise in a credit line to the material. If material is not included in the article's Creative Commons licence and your intended use is not permitted by statutory regulation or exceeds the permitted use, you will need to obtain permission directly from the copyright holder. To view a copy of this licence, visit http://creativecommons.org/licenses/by/4.0/. 


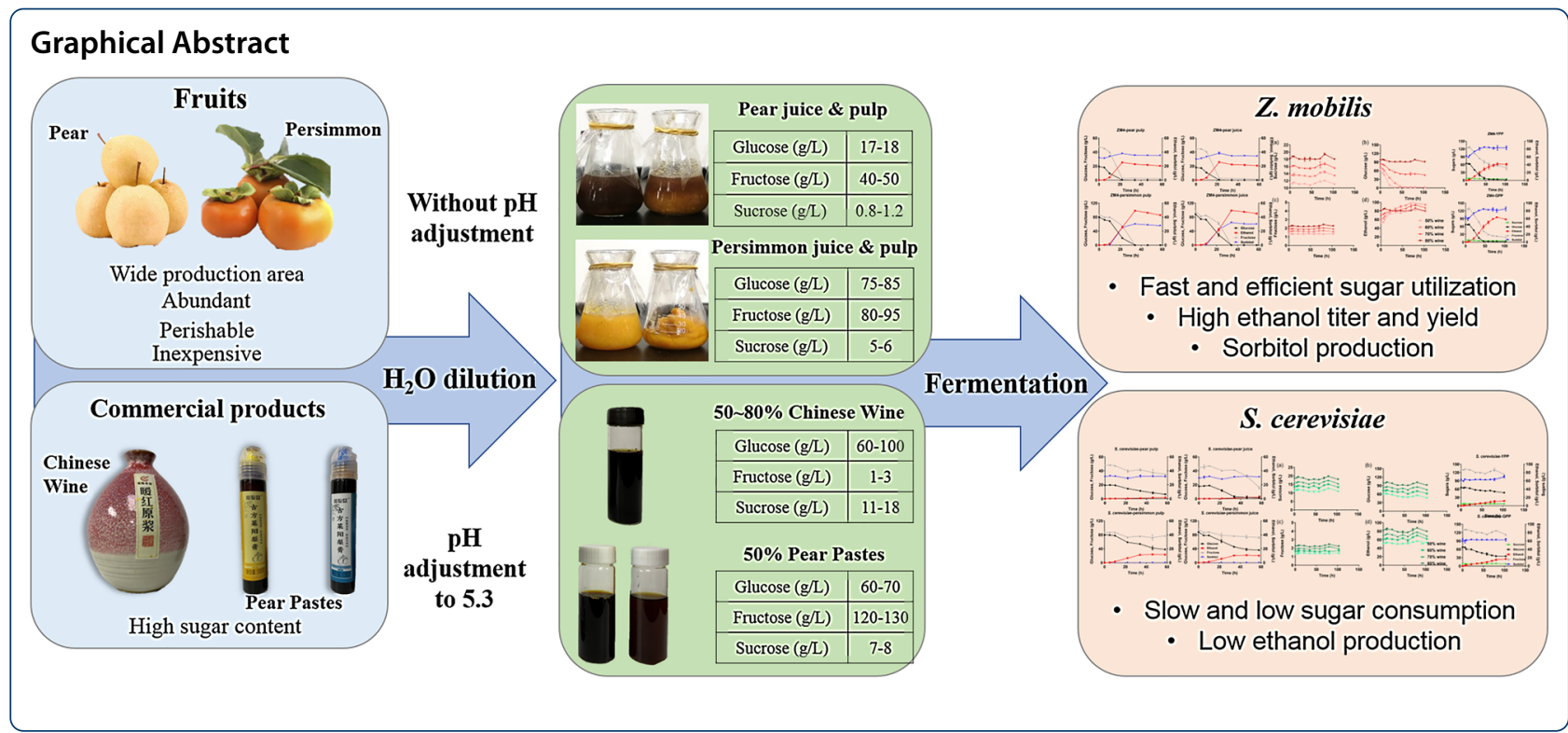

\section{Introduction}

Consumption of high-sugar content drinks and products affect the absorption of nutrients such as protein and vitamins, and increase the risk of kidney stones, obesity, diabetes, cardiovascular disease, oral diseases, and even cancers (Bantle et al. 2009; Delli Bovi et al. 2017; Febbraio et al. 2021; Johnson et al. 2018; Kohn et al. 2017; Taylor et al. 2021). To promote development of the lowsugar-content industry, many countries and regions have propagated and promoted sugar reduction to be under mandatory national control, and have also gradually formulated and promulgated the taxation policy for highsugar-content foods. Besides controlling the diet and pharmacotherapy treatment (Apovian and Gokce 2012), different strategies have been developing to address the dilemma associated with the popularity of consuming high-sugar-content products and the pursuit of a healthy lifestyle with the usage of sugar substitutes such as sugar alcohols and artificial sweeteners. Common sugar alcohols include xylitol, erythritol, and sorbitol that can be derived from sugars, but have lower caloric content than sugars.

Sugars in fruits and some commercial high-sugar-content products in some cases are difficult and/or complicated to be reduced or replaced with sugar substitute due to the manufacturing techniques and processes used. The classical industrial ethanologen Saccharomyces cerevisiae is usually used for fruit wine production. For example, S. cerevisiae SY was used to ferment Dangshan pear with $14.10 \pm 0.27 \%(\mathrm{v} / \mathrm{v})$ ethanol produced from an initial $240 \mathrm{~g} / \mathrm{L}$ total sugar within 15 days (Yang et al. 2019). Yeast was also used to ferment banana (Idise and Odum 2011), and pomegranate juice with $10.91 \pm 0.27 \%(\mathrm{v} / \mathrm{v})$ ethanol produced under a lower temperature less than 22 ${ }^{\circ} \mathrm{C}$ and a long fermentation time (Berenguer et al., 2016). Other microorganisms were also used with yeast to ferment sugars in the fruits. For example, S. cerevisiae and Acetobacter aceti were used to ferment waste pineapple residues for the production of fruit wine and vinegar in two consecutive steps for approximately 40 days with a final 7\% (v/v) ethanol and 5\% (v/v) acetic acid obtained (Roda et al. 2017).

Zymomonas mobilis is another model ethanologen, which has been traditionally used to make the alcoholic beverage "Pulque" in Central Mexico from the fermented sap of the agave plant for more than one thousand years. Zymomonas sp. was also isolated in juices from fruits and plants, such as cider and ale (Millis 1956). Due to its unique physiological characteristics and ideal industrial biocatalyst properties such as high sugar uptake and utilization efficiency, high osmolarity and ethanol tolerance, and high ethanol yield, significant efforts have been made to further understand and engineer Zymomonas as a robust microbial cell factory for lignocellulosic bioproducts. Many omics studies have already been performed and genetic engineering techniques developed, such as different CRISPR-Cas techniques (Jacobson et al. 2019; Jones-Burrage et al. 2019; Liu et al. 2020; Martien et al. 2019; Ong et al. 2020; Shen et al. 2019; Stoneman et al. 2020; Tatli et al. 2019; Vera et al. 2020; Zheng et al. 2019).

Although Z. mobilis could be an ideal host for lignocellulosic bioproducts, it is disadvantageous for bioethanol production using grains since it does not have enzymes such as amylase and maltase to utilize sugars other than sucrose, glucose, and fructose (Xia et al. 2019). It seems that the high sugar environment of fruit saps that $Z$. 
mobilis evolved to thrive in shaped its capability of utilizing sugars of sucrose, glucose, and fructose that usually exist in fruits, and the unique features of its hopanoid membrane structure and anaerobic Entner-Doudoroff (ED) pathway with efficient enzymes of pyruvate decarboxylase (Pdc) and alcohol dehydrogenases (Adhs) help it tolerate and efficiently utilize high concentration sugars for high ethanol production and tolerance (Brenac et al. 2019; Felczak et al. 2021; Todhanakasem et al. 2020; Wang et al. 2018; Yang et al. 2021) (Additional file 1: Fig. S1).

Moreover, Z. mobilis can produce levan by levansucrase SacB when sucrose is present in the media or produce sorbitol by glucose-fructose oxidoreductase (Gfo, EC 1.1.1.99) when either sucrose or both fructose and glucose are present is used (Jonas and Silveira 2004; Liu et al. 2010; Silbir et al. 2014; Tastan et al. 2019) (Additional file 1: Fig. S1). Although it is not economic to use Z. mobilis for bioethanol production using grains due to the formation of sorbitol and levan, which significantly compromise ethanol yield, it could be advantageous for applying Z. mobilis in food industry. Sorbitol is used in the food industry as a sweetener, humectant, and softener (Rice et al. 2020; Silveira and Jonas 2002), which can be found in many fruits, such as berries, pears, and apples (Jonas and Silveira 2004). The formation of sorbitol could also provide $Z$. mobilis protection under high osmotic environments such as the high sugar and ethanol conditions (Loos et al. 1994; Parker et al. 1997).

Compared with yeast, $Z$. mobilis metabolizes glucose faster and produces ethanol more efficiently than S. cerevisiae with a higher ethanol yield due to its unique anaerobic ED pathway and efficient Pdc and Adh enzymes resulting in less ATP and biomass produced for more sugar to be used in ethanol production
(Todhanakasem et al. 2020; Yang et al. 2016, 2021). In addition, as a Gram-negative facultative anaerobic bacterium, $Z$. mobilis does not need oxygen control during fermentation, which can help simplify the fermentation processing and reduce infrastructure investment and fermentation cost.

Despite the excellent features discussed above, the intrinsic capability that $Z$. mobilis has to efficiently consume sugars of sucrose, glucose, and fructose in high sugar environments for high ethanol production as a microbial biocatalyst has not been fully explored and applied in the food industry-especially the sugar reduction of high-sugar-content fruits and commercial products (Aziz 2011; Musatti et al. 2018). We chose several high-sugar-content fruits and commercial products that are typical and popular in China to investigate the sugar reduction capability of $Z$. mobilis in these materials.

In this study, we evaluated and compared the performance of two ethanologens of Z. mobilis and S. cerevisiae to ferment sugars in two common fruits being pear and persimmon as well as three high-sugar-content commercial products being two traditional pear pastes and one Chinese traditional wine. Our work demonstrated that $Z$. mobilis, a fascinating probiotic bacterial ethanologen with the capability to produce sugar substitute of sorbitol and levan-type prebiotics, is an ideal microorganism for sugar reduction and sugar-free prebiotic beverages and products.

\section{Materials and methods \\ Preparation of fermentation media using fruits and high-sugar products}

Seasonal fresh fruits of Hebei Snow Pears and Guangxi persimmons were purchased from local grocery stores in

Table 1 Recipe of fermentation media used in this study and initial concentrations of sugars and sorbitol in the media

\begin{tabular}{|c|c|c|c|c|c|c|}
\hline \multirow[t]{2}{*}{ Materials } & \multirow[t]{2}{*}{ Recipe } & \multicolumn{5}{|c|}{ Initial concentration (g/L) } \\
\hline & & Sucrose & Glucose & Fructose & Ethanol & Sorbitol \\
\hline $50 \%$ CTW & 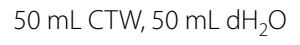 & $11.54 \pm 0.05$ & $61.95 \pm 0.01$ & $1.16 \pm 0.33$ & $51.68 \pm 0.13$ & 0 \\
\hline $60 \%$ CTW & 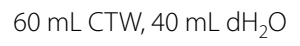 & $13.58 \pm 0.16$ & $72.52 \pm 0.73$ & $1.64 \pm 0.02$ & $59.66 \pm 0.90$ & 0 \\
\hline $70 \%$ CTW & 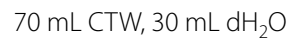 & $15.89 \pm 0.03$ & $84.97 \pm 0.05$ & $1.95 \pm 0.06$ & $70.87 \pm 0.13$ & 0 \\
\hline $80 \%$ CTW & 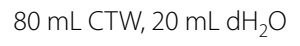 & $18.12 \pm 0.07$ & $96.75 \pm 0.49$ & $2.17 \pm 0.01$ & $80.08 \pm 0.24$ & 0 \\
\hline YPP & 130 g pear paste, & $7.02 \pm 0.08$ & $64.71 \pm 0.20$ & $129.52 \pm 0.81$ & 0 & $62.30 \pm 1.75$ \\
\hline GPP & 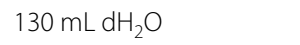 & $7.90 \pm 0.09$ & $67.38 \pm 0.66$ & $129.12 \pm 1.17$ & 0 & $62.05 \pm 4.08$ \\
\hline Pear pulp & 320 g pear, & $1.20 \pm 0.05$ & $17.71 \pm 2.25$ & $50.55 \pm 3.87$ & 0 & $33.49 \pm 2.49$ \\
\hline Pear juice & $50 \mathrm{~mL} \mathrm{dH_{2 }} \mathrm{O}$ & $0.98 \pm 0.02$ & $17.89 \pm 2.45$ & $44.51 \pm 2.59$ & 0 & $29.46 \pm 3.31$ \\
\hline Persimmon pulp & 320 g persimmon, & $5.02 \pm 1.14$ & $75.79 \pm 2.43$ & $81.88 \pm 3.64$ & 0 & 0 \\
\hline Persimmon juice & $100 \mathrm{~mL} \mathrm{dH} \mathrm{H}_{2} \mathrm{O}$ & $5.55 \pm 1.58$ & $85.89 \pm 3.33$ & $93.48 \pm 3.84$ & 0 & 0 \\
\hline
\end{tabular}

$\mathrm{dH}_{2} \mathrm{O}$ distilled water, $C T W$ Chinese traditional wine, YPP yellow pear paste, GPP green pear paste 
Wuhan, China. The reason for selecting these two fruits is because of their availability, cost, and sugar content. Persimmon production in China is abundant, accounting for 43\% of the world's production in 2013 (Zou et al. 2017). Although ripe persimmon fruits are full of nutrients such as protein, vitamins, minerals, and dietary fibers (Hwang et al. 2017; Zhu et al. 2014), persimmons have thin skin and fast ripening period, resulting in a short shelf life (Hidalgo et al. 2012). Therefore, diverse and efficient strategies are needed to fully utilize these fruits before they are spoiled.

High-sugar-content commercial products of yellow pear paste (YPP) and green pear paste (GPP), cough syrups made of pears used in Traditional Chinese Medicine, were supplied by LingHang Food Company (Shandong, China). The high-sugar-content alcoholic product of Chinese traditional wine (CTW) was provided by WenTianGe Biological Company (Shandong, China).

Clean and dry pears and persimmons were directly diced into small pieces without removing fruit peels to generate a fruit slurry. Half of the fruit slurry was directly used as fruit pulp for fermentation after adding distilled water $\left(\mathrm{dH}_{2} \mathrm{O}\right)$, and the other half was filtered through filter paper to remove solid materials in the slurry as fruit juice. Commercial products of YPP, GPP, and CTW were also diluted using $\mathrm{dH}_{2} \mathrm{O}$ (Table 1).

The initial pHs of CTW, YPP, and GPP were $\mathrm{pH} 4.0$, 4.50 , and 4.65, respectively, which were then adjusted to a $\mathrm{pH}$ of 5.3 using $1 \mathrm{~N} \mathrm{KOH}$ and $\mathrm{HCl}$. The initial $\mathrm{pH}$ of pear fruit and pulp was $\mathrm{pH} 5.3$, and the initial $\mathrm{pH}$ of persimmon fruit and pulp was $\mathrm{pH}$ 5.6; these were used directly without $\mathrm{pH}$ adjustment. The product diagrams of raw materials and pictures of processed fruits and commercial high-sugar-content products are included in Additional file 1: Fig. S2. Detailed information on the recipe as well as the initial concentrations of sugars and sorbitol in the fermentation media is shown in Table 1.

\section{Strains and growth conditions}

Zymomonas mobilis subsp. mobilis ZM4 (ATCC 31821) (Seo et al. 2005) and Saccharomyces cerevisiae BY4743 were used in this study. Z. mobilis ZM4 was cultured in Rich Medium (RM: $10 \mathrm{~g} / \mathrm{L}$ yeast extract, $2 \mathrm{~g} / \mathrm{L} \mathrm{KH}_{2} \mathrm{PO}_{4}$, with different concentration of glucose or fructose, $\mathrm{pH}$ 5.8) at $30{ }^{\circ} \mathrm{C}$ without shaking as previously described (Yang et al. 2020). The sugars used in RMG5, RMG10, RMF5.5, RMF11, RMG5F5.5, and RMG10F11 were $50 \mathrm{~g} / \mathrm{L}$ glucose, $100 \mathrm{~g} / \mathrm{L}$ glucose, $55 \mathrm{~g} / \mathrm{L}$ fructose, $110 \mathrm{~g} / \mathrm{L}$ fructose, $50 \mathrm{~g} / \mathrm{L}$ glucose and $55 \mathrm{~g} / \mathrm{L}$ fructose, $100 \mathrm{~g} / \mathrm{L}$ glucose and $110 \mathrm{~g} / \mathrm{L}$ fructose, respectively. S. cerevisiae was cultivated in sterile Yeast Peptone Dextrose (YPD) broth (10 g/L yeast extract, $20 \mathrm{~g} / \mathrm{L}$ peptone, $20 \mathrm{~g} / \mathrm{L}$ glucose) at $30{ }^{\circ} \mathrm{C}$ with shaking at $200 \mathrm{rpm}$.

\section{Fermentation}

Cell cultures grown as mentioned above to the logarithmic phase were centrifuged at $4000 \mathrm{rpm}$ for $10 \mathrm{~min}$ at room temperature and washed once with sterile water. They were then resuspended and added in $40 \mathrm{~mL}$ fermentation medium in a 50-mL flask. The fermentation condition was $30{ }^{\circ} \mathrm{C}$ without shaking with an initial OD $600 \mathrm{~nm}$ value of 0.15 for $Z$. mobilis and $30{ }^{\circ} \mathrm{C}, 200 \mathrm{rpm}$ shaking with an initial OD $600 \mathrm{~nm}$ value of 0.50 for $S$. cerevisiae. Each experiment was performed in triplicates, and cultures were sampled at different time points postinoculation to monitor cell growth and concentrations of fructose, glucose, sucrose, ethanol, and sorbitol during fermentation.

\section{Analytical methods}

Cell growth in terms of its optical density at $600 \mathrm{~nm}$ was monitored with a UV-visible spectrophotometer UV-1800 (AoYi Instrument Co., Ltd, Shanghai, China). Samples were centrifuged at 12,000 rpm for $2 \mathrm{~min}$, and supernatants were filtered using a $0.45-\mu \mathrm{m}$ filter. The concentrations of sucrose, glucose, fructose, ethanol, and sorbitol were determined by high-performance liquid chromatography (HPLC, Shimadzu, Japan) equipped with a refractive index detector (RID) and a column of Bio-Rad Aminex HPX- $87 \mathrm{H}(300 \times 7.8 \mathrm{~mm})$. The mobile phase was $0.005 \mathrm{M} \mathrm{H}_{2} \mathrm{SO}_{4}$ with a flow rate of $0.5 \mathrm{~mL} / \mathrm{min}$, and the temperatures of detector and column were 40 and $60{ }^{\circ} \mathrm{C}$, respectively. The concentration of sucrose was determined using a flow rate of $0.3 \mathrm{~mL} / \mathrm{min}$, and the temperatures of 35 and $18{ }^{\circ} \mathrm{C}$ for detector and column were used, respectively, to avoid the digestion of sucrose in the hot dilute acid (Duarte-Delgado et al. 2015).

The total consumed sugar $\left(C_{\text {Total }}\right)$ was calculated according to the following formulas:

$$
C_{\text {Total }}=(S * 0.526+G)+(S * 0.526+F) .
$$

In this equation, " $S$ " means sucrose consumed, " $G$ " means glucose consumed, and " $F$ " means fructose consumed. " 0.526 " is the theoretical yield from sucrose into glucose and fructose.

When sorbitol was produced in media containing both fructose and glucose, the total sugars consumed for ethanol and other end-products $\left(C_{\text {Ethanol }}\right)$ was calculated according to the following formula with the fructose used for sorbitol production subtracted:

$$
C_{\text {Ethanol }}=C_{\text {Total }}-\text { Sorbitol } / 1.011 .
$$

"Sorbitol" means the amount of sorbitol produced. "1.011" is the theoretical yield from fructose into sorbitol.

The ethanol yield $\left(Y_{E}\right)$ is calculated according to the following formulas (Günan Yücel and Aksu 2015): 


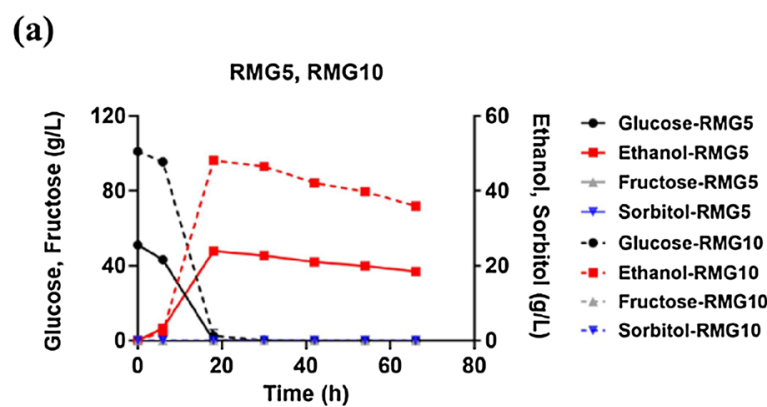

(c)

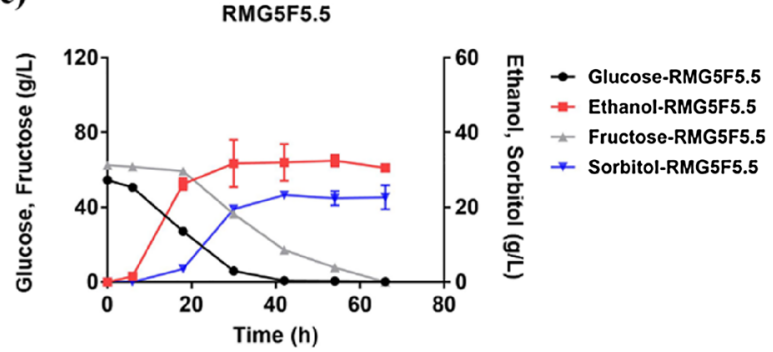

(b)

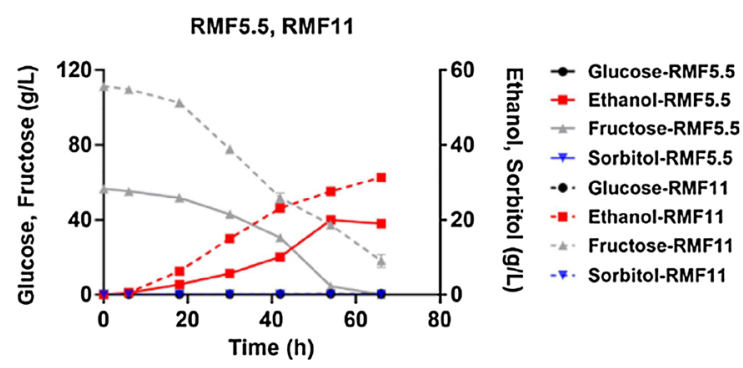

(d)

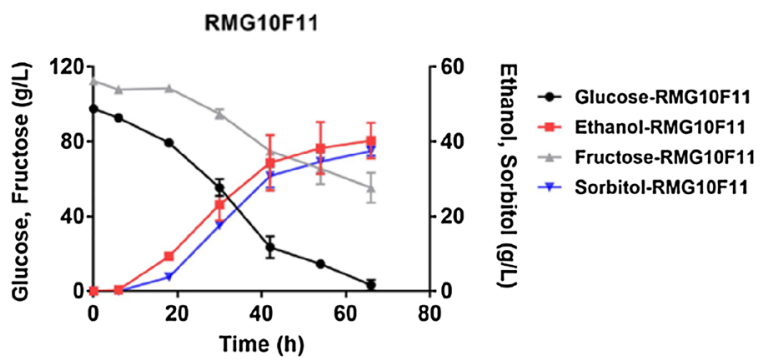

Fig. 1 Fermentation performance of Z. mobilis in RM medium including the consumption of glucose (black circle) and fructose (grey triangle) as well as the production of ethanol (red square) and sorbitol (blue inverted triangle) in RMG5 and RMG10 (a), RMF5.5 and RMF11 (b), RMG5F5.5 (c), and RMG10F11 (d)

$$
Y_{E}=g \text { max ethanol } / C_{\text {Ethanol }} \text {. }
$$

In this equation, "g max ethanol" is the maximum theoretical ethanol produced.

The theoretical ethanol yield $\left(Y_{E} \%\right)$ is calculated according to the following formula (Demiray et al. 2019):

$$
Y_{E} \%=\left[g \text { max ethanol } /\left(C_{\text {Ethanol }} * 0.511\right)\right] * 100 .
$$

\section{Statistical analysis}

Data were analyzed by $t$-tests or one-way ANOVA using the GraphPad Prism statistical software (version 8.0.1). $p<0.05$ was considered as statistically significant difference.

\section{Results and discussion}

\section{Fermentation performance of $Z$. mobilis in pure sugars} of glucose and fructose

$Z$. mobilis was cultured directly in pure sugars of glucose, fructose, as well as mixed sugars of glucose and fructose in different concentrations of RMG5, RMG10, RMF5.5, RMF11, RMG5F5.5, and RMG10F11 to compare sugar utilization as well as ethanol and sorbitol production. Our results demonstrated that glucose is the preferable sugar compared to fructose for Z. mobilis, and sorbitol cannot be produced by $Z$. mobilis in monosaccharide medium of glucose or fructose (Fig. 1).
Within $20 \mathrm{~h}$ post-inoculation, all glucose up to the highest $100 \mathrm{~g}$ used in this study was consumed with an ethanol yield around $0.48 \mathrm{~g} / \mathrm{g}$, while it took more than $60 \mathrm{~h}$ to utilize $55 \mathrm{~g}$ fructose with an ethanol yield around $0.35 \mathrm{~g} / \mathrm{g}$ (Fig. 1a, b; Table 2). In addition, the presence of fructose in the mixed sugars of glucose and fructose severely impeded the glucose utilization despite that glucose was still consumed first following by a concurrent utilization of glucose and fructose and simultaneous production of ethanol and sorbitol (Fig. 1c, d; Table 2). Sorbitol formation in Z. mobilis fermentations is a result of glucose-fructose oxidoreductase (Gfo), which is involved in the complete catalytic cycle of oxidation of glucose to gluconate with concomitant reduction of fructose to sorbitol (Additional file 1: Fig. S1).

\section{Application and comparison of $Z$. mobilis with yeast for sugar reduction in fruits}

Sugar utilization capability of $Z$. mobilis in high-sugarcontent fruits was then investigated using two fresh fruits of pear and persimmon with minimal processing of adding distilled water to the fruit slurries. Hebei snow pear used in this study contained ca. $30 \mathrm{~g} / \mathrm{L}$ sorbitol while the concentrations of fructose and glucose were low (ca. $60 \mathrm{~g} / \mathrm{L}$ ) compared to those in Guangxi persimmon, which had no sorbitol detected but contained ca. $160 \mathrm{~g} / \mathrm{L}$ total sugars of fructose and glucose (Table 1). 


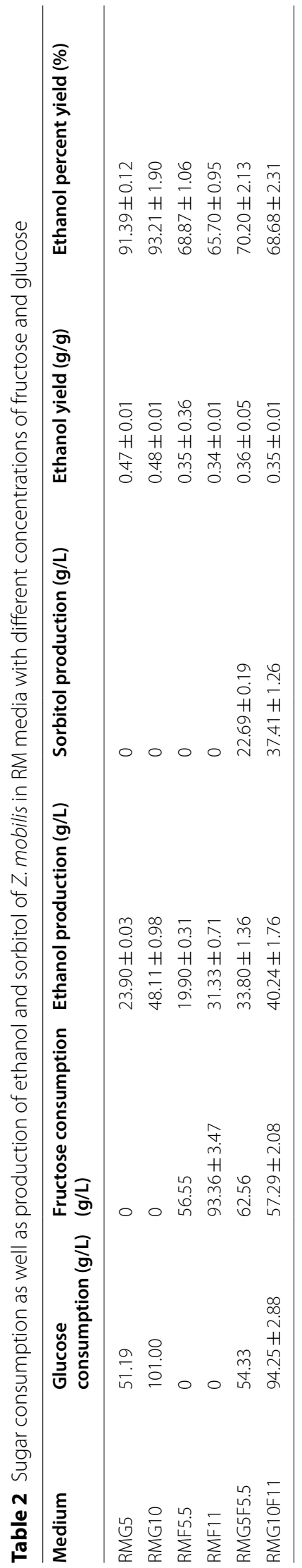


Table 3 Sugar consumption as well as the production of ethanol and sorbitol of Z. mobilis in fruit juice and pulp

\begin{tabular}{lllllll}
\hline & $\begin{array}{l}\text { Glucose } \\
\text { consumption (g/L) }\end{array}$ & $\begin{array}{l}\text { Fructose } \\
\text { consumption (g/L) }\end{array}$ & $\begin{array}{l}\text { Ethanol } \\
\text { production (g/L) }\end{array}$ & $\begin{array}{l}\text { Sorbitol } \\
\text { production (g/L) }\end{array}$ & Ethanol yield (g/g) & $\begin{array}{l}\text { Ethanol } \\
\text { percent yield } \\
\mathbf{( \% )}\end{array}$ \\
\hline Pear pulp & 19.30 & $45.49 \pm 0.05$ & $20.31 \pm 0.73$ & $3.43 \pm 0.56$ & $0.33 \pm 0.01$ & $64.75 \pm 2.72$ \\
Pear juice & 17.89 & $43.20 \pm 1.18$ & $20.68 \pm 0.24$ & $4.88 \pm 0.87$ & $0.37 \pm 0.01$ & $71.98 \pm 2.32$ \\
Persimmon pulp & 79.64 & 86.57 & $42.79 \pm 0.74$ & $27.76 \pm 0.11$ & $0.31 \pm 0.01$ & $60.36 \pm 1.01$ \\
Persimmon juice & 87.92 & 96.20 & $45.09 \pm 0.90$ & $30.04 \pm 0.45$ & $0.29 \pm 0.01$ & $57.15 \pm 1.02$ \\
\hline
\end{tabular}

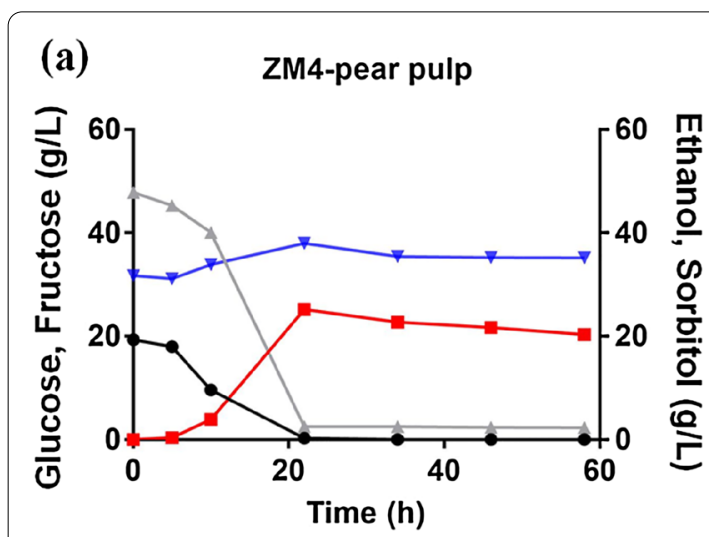

(b)

(c)

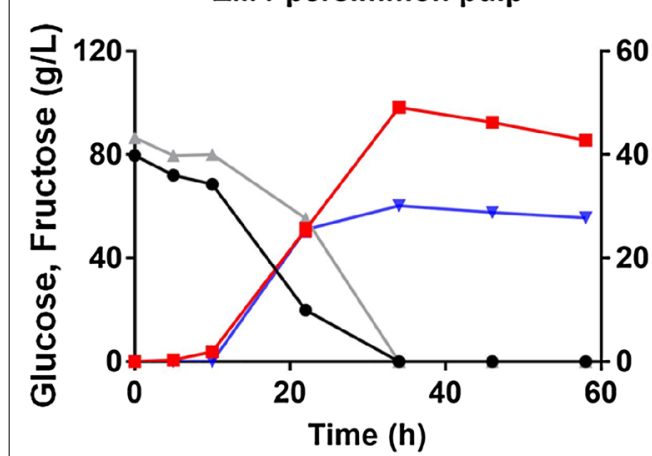

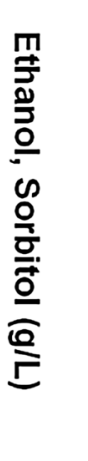

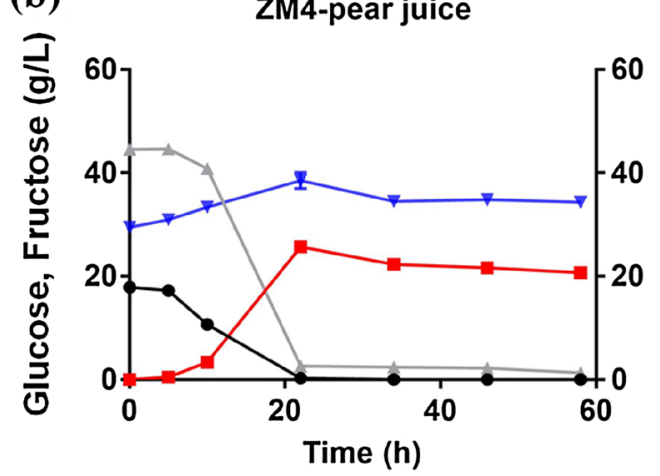

(d)

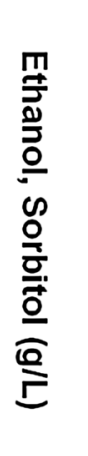

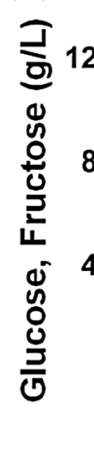

ZM4-persimmon juice

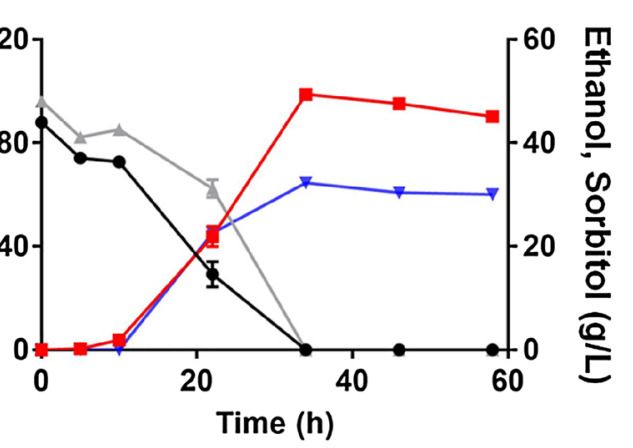

Fig. 2 Concentration changes of glucose (black circle), ethanol (red square), fructose (grey triangle), and sorbitol (blue inverted triangle) during fermentation by Z. mobilis in pear pulp (a), pear juice (b), persimmon pulp (c), and persimmon juice (d), respectively. There was no significant difference for $Z$. mobilis fermentation in both fruit pulp and juice with $T$-test $p$-value greater than 0.05

Z. mobilis can utilize all sugars in the fruit juices and pulps with ca. $20 \mathrm{~g} / \mathrm{L}$ and $40 \mathrm{~g} / \mathrm{L}$ ethanol produced from pear and persimmon fruits, respectively (Table 3; Fig. 2). The noticeable bubbles observed during fermentation in fruit juices and the pores formed during fermentation using persimmon pulp could be due to the release of carbon dioxide from cell growth and sugar metabolism, which also suggests that $Z$. mobilis can utilize sugars efficiently in the fruit juices and pulps.

Fermentation experiments using pear and persimmon were repeated three and six times, respectively. The
R-squared values among different batches of experiments ranging from 0.93 to 0.99 demonstrated the great reproducibility of using $Z$. mobilis for sugar reduction in highsugar-content fruits (Additional file 1: Fig. S3).

Comparing persimmon with pear, it took Z. mobilis more time to consume sugars in persimmon fruit than in pears. This may be due to higher total sugar contents of glucose and fructose in persimmon fruits than those in pear (Tables 1, 3; Fig. 2). In addition, more sorbitol was produced using persimmon fruit than when using pear fruit, reaching a similar total amount around $30 \mathrm{~g} / \mathrm{L}$ 


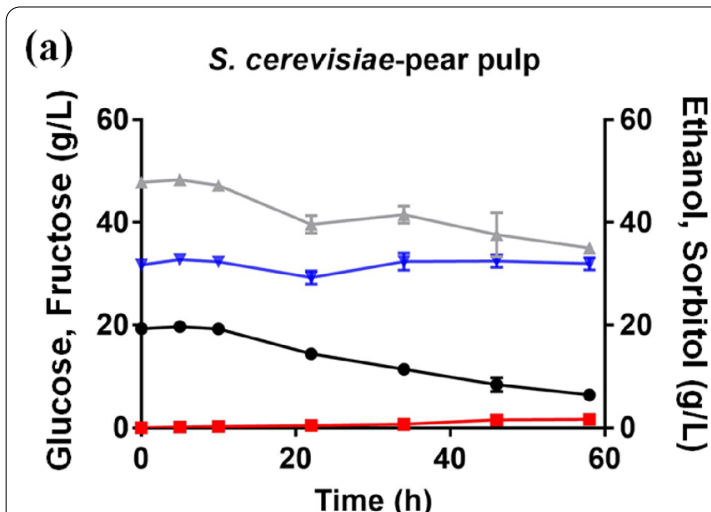

(c) S. cerevisiae-persimmon pulp

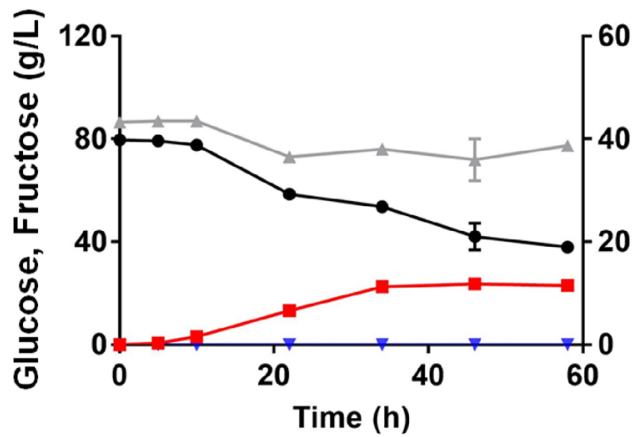

(b)

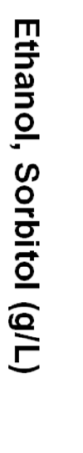

(d)

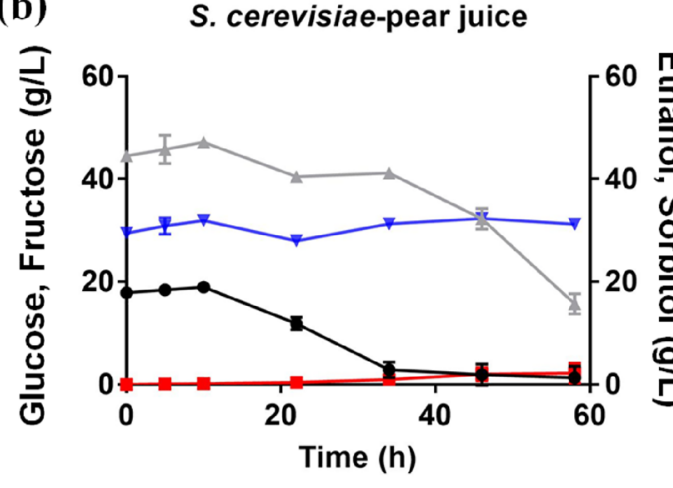

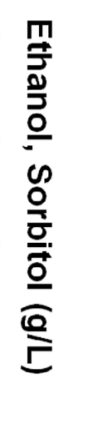

Fig. 3 Concentration changes of glucose (black circle), ethanol (red square), fructose (grey triangle), and sorbitol (blue inverted triangle) during fermentation by S. cerevisiae in pear pulp (a), pear juice (b), persimmon pulp (c), and persimmon juice (d), respectively. There were significant differences for glucose consumption ( $p$-value $=0.02$ ) and sorbitol production ( $p$-value $=0.008$ ) using pear pulp and pear juice

after fermentation and resulting in a lower ethanol yield (Table 3; Fig. 2).

The fermentation performance of the classical industrial ethanologen yeast was also investigated using pear and persimmon fruits. Our results indicated that although yeast can also utilize glucose and fructose in the fruit juices and pulps, it took a longer time to utilize only part of the sugars in the media and produced a little amount of ethanol and no sorbitol (Fig. 3). There was more than half $(35.04 \pm 0.40 \mathrm{~g} / \mathrm{L})$ and one-third $(15.75 \pm 1.97 \mathrm{~g} / \mathrm{L})$ fructose left after $60 \mathrm{~h}$ fermentation by $S$. cerevisiae in the pear pulp and juice, respectively (Fig. 3a, b). The ethanol yield using persimmon by $S$. cerevisiae was higher than that of using pear, which was up to $0.23 \pm 0.01 \mathrm{~g} / \mathrm{g}$ (Fig. 3c, d). However, the sugars were consumed much slower by yeast than $Z$. mobilis (Fig. 2) with a significant amount of glucose left in the media and only a small amount of fructose being utilized $60 \mathrm{~h}$ post-inoculation (Fig. 3). Therefore, Z. mobilis was more suitable than $S$. cerevisiae BY4743 to reduce sugars quickly and efficiently in pear and persimmon fruits with minimal processing.

Table 4 Sugar consumption and ethanol conversion rate of Z. mobilis in pear paste

\begin{tabular}{lllllll}
\hline & $\begin{array}{l}\text { Sucrose } \\
\text { consumption } \\
(\mathbf{g} / \mathbf{L})\end{array}$ & $\begin{array}{l}\text { Glucose } \\
\text { consumption } \\
(\mathbf{g} / \mathbf{L})\end{array}$ & $\begin{array}{l}\text { Fructose } \\
\text { consumption } \\
(\mathbf{g} / \mathbf{L})\end{array}$ & $\begin{array}{l}\text { Ethanol } \\
\text { production } \\
(\mathbf{g} / \mathbf{L})\end{array}$ & $\begin{array}{l}\text { Sorbitol } \\
\text { production (g/L) }\end{array}$ & $\begin{array}{l}\text { Ethanol yield (g/g) } \\
\text { percent } \\
\text { yield }(\%)\end{array}$ \\
\hline YPP & $1.61 \pm 0.15$ & $63.46 \pm 0.21$ & $82.43 \pm 2.82$ & $41.10 \pm 2.51$ & $20.90 \pm 1.50$ & $0.33 \pm 0.02$ \\
GPP & $2.72 \pm 0.19$ & $66.79 \pm 0.71$ & $111.88 \pm 2.66$ & $58.11 \pm 0.60$ & $23.18 \pm 1.22$ & $0.37 \pm 0.01$ \\
\hline
\end{tabular}

YPP yellow pear paste, GPP green pear paste 


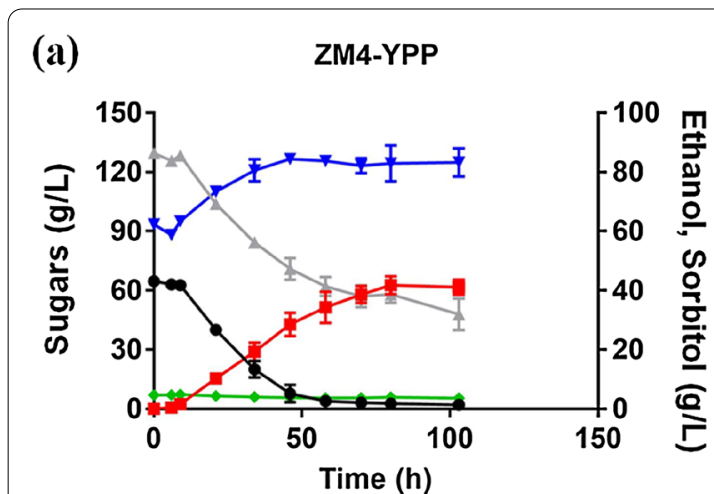

(c)
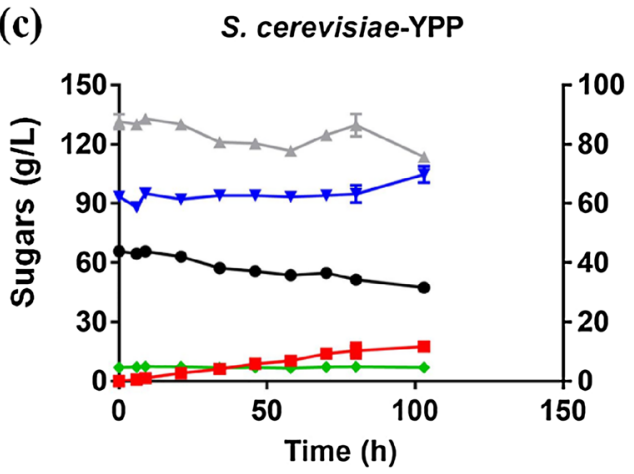

(b)

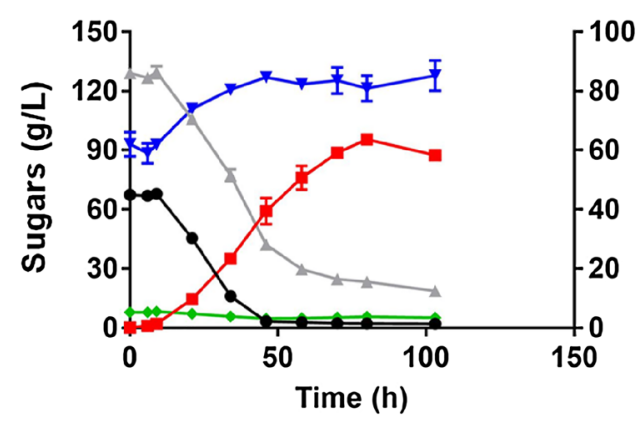

(d)

S. cerevisiae-GPP
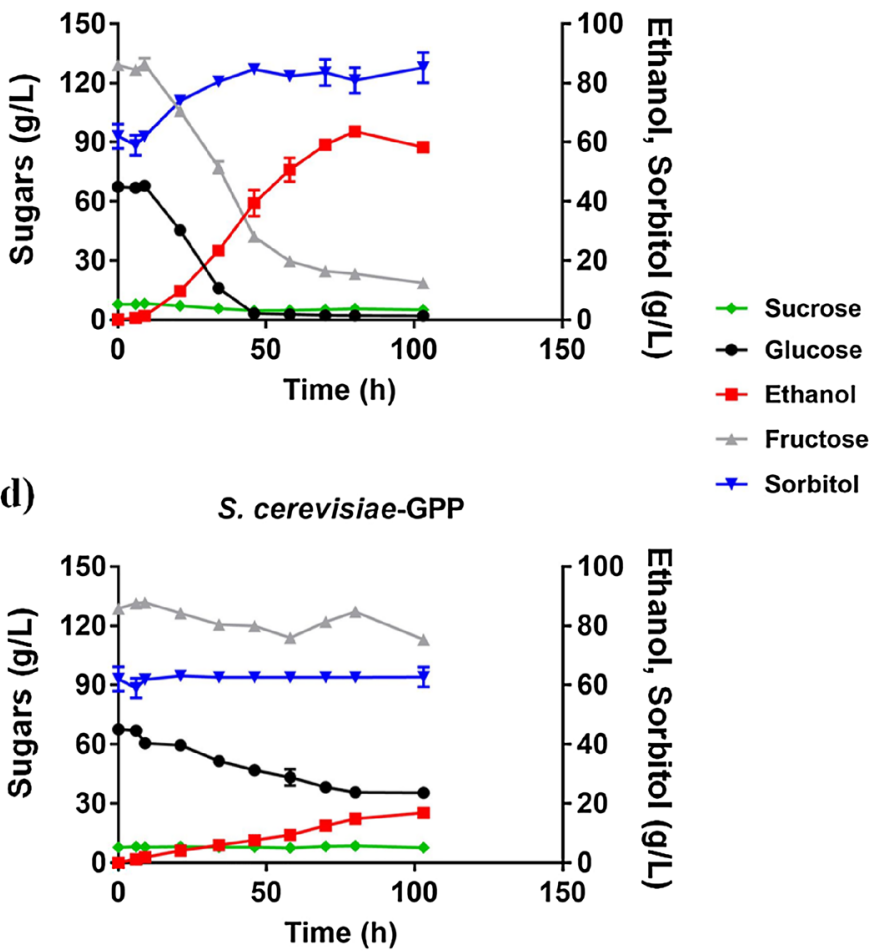

Fig. 4 Concentration changes of sucrose (green diamond), glucose (black circle), ethanol (red square), fructose (grey triangle), and sorbitol (blue inverted triangle) during fermentation in pear pastes of yellow pear paste (YPP, a) and green pear paste (GPP, b) by Z. mobilis as well as those by $\mathrm{S}$. cerevisiae in YPP (c) and GPP $(\mathbf{d})$, respectively. There were significant differences for fructose consumption and ethanol production in GPP and YPP for Z. mobilis, as well as glucose consumption and ethanol production in GPP and YPP for S. cerevisiae with a T-test $p$-value $\leq 0.01$

\section{Application and comparison of $Z$. mobilis with yeast} for sugar reduction in commercial high-sugar products

We further examined the sugar reduction capabilities of Z. mobilis in two commercial products: yellow pear paste (YPP) and green pear paste (GPP). The major components of sugars glucose and fructose as well as sorbitol in the pear pastes (PPs) are similar to those in the pear fruit containing significant amounts of sorbitol $(>60 \mathrm{~g} / \mathrm{L})$ and onefold more fructose (ca. $130 \mathrm{~g} / \mathrm{L}$ ) than glucose (Table 1). The major difference between GPP and YPP is the medium color of GPP was lighter than that of YPP (Additional file 1: Fig. S2), and the sucrose and glucose concentrations in GPP were slightly higher than those in YPP (Table 1).

Z. mobilis can consume all glucose $(>60 \mathrm{~g} / \mathrm{L})$ within $50 \mathrm{~h}$ post-inoculation and most fructose $(>80 \mathrm{~g} / \mathrm{L})$ with similar amounts of sorbitol produced $(>20 \mathrm{~g} / \mathrm{L})$ in the PPs (Table 4; Fig. 4a, b). However, Z. mobilis consumed fructose slower in YPP than that in GPP with more than $30 \mathrm{~g} / \mathrm{L}$ fructose left and $40 \%$ less ethanol produced correspondingly. The final alcohol concentrations in YPP and GPP were $41.10 \pm 2.51 \mathrm{~g} / \mathrm{L}$ and $58.11 \pm 0.60 \mathrm{~g} / \mathrm{L}$ with ethanol percent yields of $64.50 \pm 1.12 \%$ and $73.06 \pm 1.86 \%$, respectively (Table 4; Fig. 4a, b), which is consistent with a previous study finding that ethanol yield of $Z$. mobilis SBE15 in four sugar beet substrates were reduced to $73 \sim 79 \%$ due to sorbitol formation (Park and Baratti 1991).

Similarly, the fermentation performance of yeast $S$. cerevisiae in these two pear pastes of YPP and GPP was examined (Fig. 4c, d). The results indicated that yeast also performed better in GPP than in YPP. Similar to the fermentation performance using fresh pear fruits, S. cerevisiae consumed sugars in the PPs slowly with most sugars left and little ethanol produced. For example, it only consumed about $32 \mathrm{~g}$ glucose and $16 \mathrm{~g}$ fructose with less than $17 \mathrm{~g}$ ethanol produced after fermentation completed $100 \mathrm{~h}$ post-inoculation; this was less than one-third of that produced by Z. mobilis (Table 4; Fig. 4). 
Table 5 Substrate sugars consumption and ethanol conversion rate of Z. mobilis in Chinese traditional wine (CTW)

\begin{tabular}{lllllll}
\hline CTW & $\begin{array}{l}\text { Sucrose } \\
\text { consumption (g/L) }\end{array}$ & $\begin{array}{l}\text { Glucose } \\
\text { consumption (g/L) }\end{array}$ & $\begin{array}{l}\text { Fructose } \\
\text { consumption (g/L) }\end{array}$ & $\begin{array}{l}\text { Ethanol } \\
\text { production (g/L) }\end{array}$ & Ethanol yield (g/g) & $\begin{array}{l}\text { Ethanol } \\
\text { percent yield } \\
(\%)\end{array}$ \\
\hline $50 \%$ & $0.45 \pm 0.14$ & $60.24 \pm 0.18$ & $0.37 \pm 0.71$ & $26.67 \pm 0.03$ & $0.44 \pm 0.01$ & $86.16 \pm 1.57$ \\
$60 \%$ & $0.09 \pm 0.20$ & $70.08 \pm 0.73$ & $0.10 \pm 0.03$ & $34.75 \pm 1.75$ & $0.50 \pm 0.03$ & $96.97 \pm 2.21$ \\
$70 \%$ & $0.27 \pm 0.12$ & $39.39 \pm 2.41$ & $0.17 \pm 0.05$ & $16.54 \pm 0.45$ & $0.42 \pm 0.04$ & $81.83 \pm 2.35$ \\
$80 \%$ & $0.15 \pm 0.24$ & $5.27 \pm 1.16$ & $0.15 \pm 0.30$ & $0.55 \pm 0.47$ & $0.10 \pm 0.06$ & $19.86 \pm 1.19$ \\
\hline
\end{tabular}

No sorbitol detected

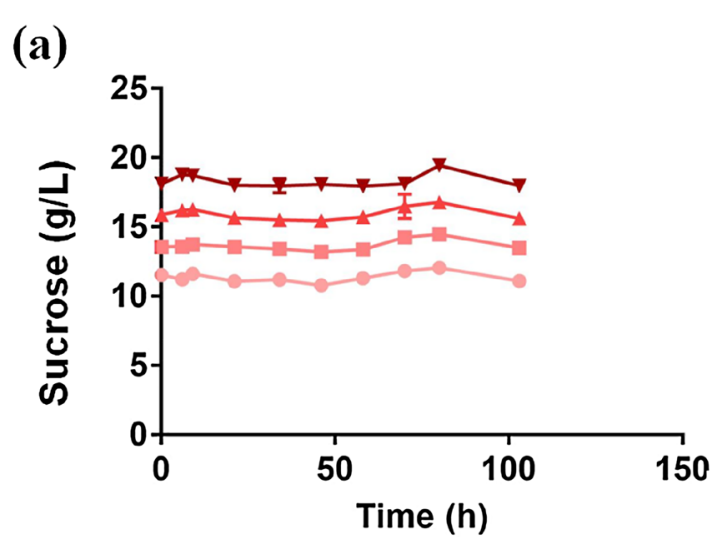

(c)

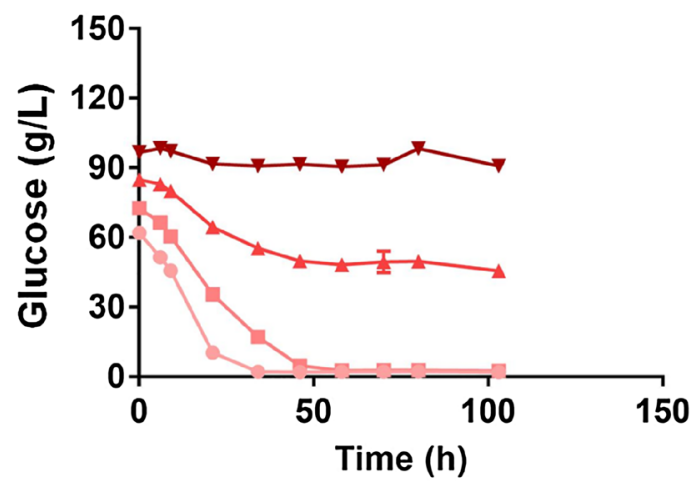

(b)

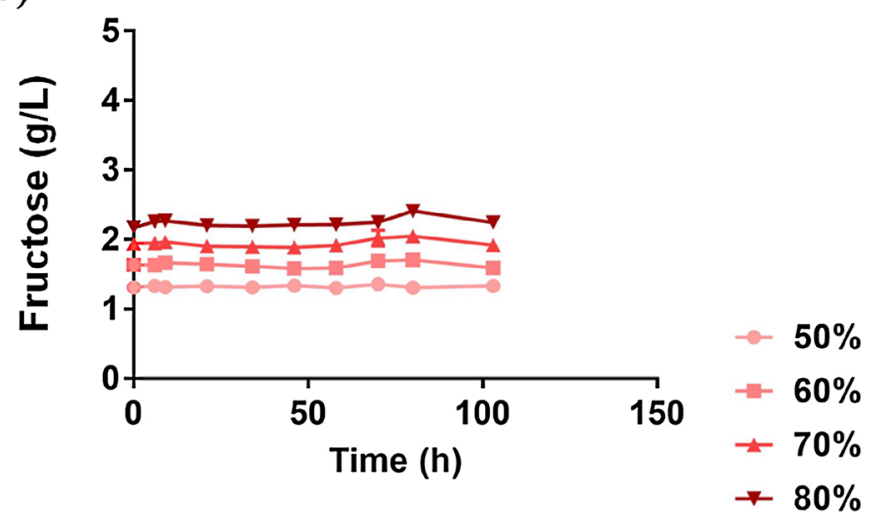

(d)

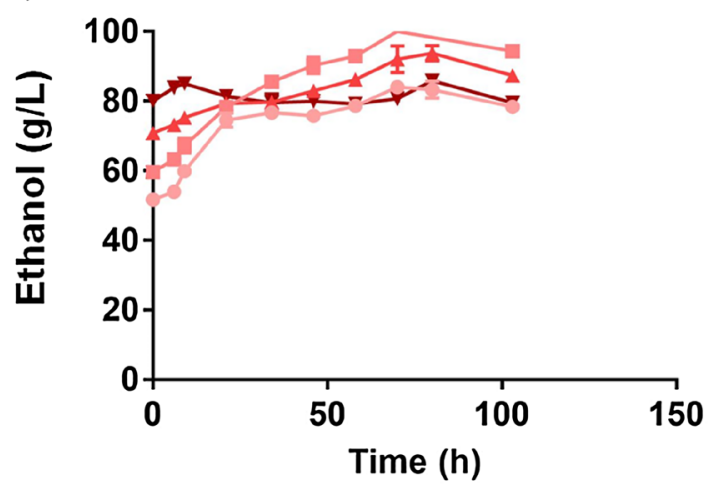

Fig. 5 Concentration changes of sucrose (a), fructose (b), glucose (c), and ethanol (d) during fermentation by Z. mobilis in Chinese traditional wine (CTW) with the dilution rates of 50\% (circle), 60\% (square), $70 \%$ (triangle), and $80 \%$ (inverted triangle), respectively. There were significant differences for glucose consumption ( $p$-value $<0.0001$ ) and ethanol production ( $p$-value $=0.035$ ) in 50\%,60\%, 70\%, and 80\% CTW using one-way ANOVA

\section{Application and comparison of Z. mobilis with yeast for sugar reduction in commercial high-sugar alcoholic products}

Chinese traditional wines are fermented alcoholic beverages brewed directly from different combinations of grains such as millet, rice, and wheat with an alcohol content around $10 \sim 20 \%$. We first measured the concentrations of ethanol and major sugars in the Chinese traditional wine (CTW), and the result exhibited that the
CTW we used in this study contained more than $100 \mathrm{~g} / \mathrm{L}$ ethanol. The majority of sugars in the CTW was glucose (>120 g/L) with ca. $20 \mathrm{~g} / \mathrm{L}$ sucrose and a small amount of fructose around $2 \mathrm{~g} / \mathrm{L}$ (Table 1 ).

Considering that the growth of $Z$. mobilis will be inhibited when ethanol concentration is above $10 \%$, we diluted the CTW with distilled water to different final concentrations of 50, 60, 70, and 80\% CTW. Z. mobilis utilized all glucose in 50\% and $60 \%$ CTW within 
2 days with $26.67 \pm 0.03$ and $34.75 \pm 1.75 \mathrm{~g} / \mathrm{L}$ ethanol produced, resulting in a final ethanol concentration of $84.06 \pm 0.51 \mathrm{~g} / \mathrm{L}$ and $100.97 \pm 1.70 \mathrm{~g} / \mathrm{L}$, respectively (Tables 1, 5; Fig. 5). Z. mobilis utilized half of the glucose in $70 \%$ CTW, but only 5 g glucose was consumed in $80 \%$ CTW. These results indicated that the optimal concentration for sugar reduction in CTW by $Z$. mobilis is $60 \%$, which had the lowest dilution but highest ethanol titer and yield (Tables 1, 5; Fig. 5).

S. cerevisiae, however, was unable to consume sugars in CTW in these concentrations (Additional file 1: Fig. S4), even when supplemented by $\mathrm{YPD}^{-}$solution into CTW to supply an exogenous nitrogen source for $S$. cerevisiae. Although S. cerevisiae BY4743 can tolerate $8 \%(\mathrm{v} / \mathrm{v})$ ethanol (Nilambari and Jadhav 2010), ethanol concentrations in 50, 60, 70 and $80 \%$ CTW were $51.68 \pm 0.13$, $59.66 \pm 0.90,70.87 \pm 0.13$, and $80.08 \pm 0.24 \mathrm{~g} / \mathrm{L}$, respectively (Table 1). Therefore, inhibitors in CTW including ethanol could impede the growth of S. cerevisiae in CTW.

Differing from conditions where fruits and pear pastes were used as the materials, no sorbitol was detected in CTW when fermented by $Z$. mobilis. This could be due to the low fructose concentration (less than $2 \mathrm{~g} / \mathrm{L}$ ) in CTW. Although CTW contains sucrose (Table 1), the SacC enzyme of $Z$. mobilis that hydrolyzes sucrose to fructose and glucose could be inhibited in a high ethanol environment, resulting in little fructose generation and sorbitol production.

CTW may also be served as medicine, which can be the case for the one used in this study. High-sugar content in these wines could cause excessive intake of sugar, which is not suitable for patients sensitive to sugar such as those with cancers or diabetes. Our study thus provides an alternative strategy to reduce sugar in high-sugar-content wines, including medicinal alcoholic drinks. Despite Z. mobilis being more advantageous than yeast for reducing sugars in materials of high-sugar-content fruits and commercial products used in this study, we only tested limited strains of $Z$. mobilis ZM4 and S. cerevisiae BY4743 under limited conditions. It is possible that other microorganisms, such as other yeast strains or other probiotic microorganisms can fulfill a similar role to $Z$. mobilis ZM4 tested in this study. In addition, although our study demonstrated that $Z$. mobilis ZM4 can reduce sugars to ethanol for diverse high-sugar-content fruits and commercial products, the complete metabolic profiles after fermentation should be investigated in the future including those that could come from the materials we used (e.g., polyphenols and minerals).

\section{Conclusions}

The potential of applying the bacterial ethanologen $Z$. mobilis for sugar reduction in high-sugar-content fruits and commercial products was evaluated and compared with the classical ethanologen yeast $S$. cerevisiae in this study. Our results demonstrated that $Z$. mobilis performed better than the yeast in high-sugar-content fruits and commercial products used in this study with a fast and efficient sugar utilization and ethanol production. In addition, the whole process is simple and economic-only requiring $\mathrm{pH}$ adjustment and appropriate dilution using water-which can easily be scaled up for commercial applications. Considering the excellent capability of Z. mobilis to produce sorbitol and levantype prebiotics as well as its unique characteristics of high ethanol yield in high sugar and ethanol environments given limited nutrient requirements for efficient fermentation demonstrated in this study, more efforts should be spent to utilize this GRAS probiotic strain for its broad applications in food industry.

\section{Abbreviations}

Adhs: Alcohol dehydrogenases; CTW: Chinese traditional wine; ED: EntnerDoudoroff; EMP: Embden-Meyerhof-Parnas; Gfo: Glucose-fructose oxidoreductase; GPP: Green pear paste; GRAS: Generally regarded as safe status; Pdc: Pyruvate decarboxylase; PPs: Pear pastes; RID: Refractive index detector; RM: Rich medium; YPD: Yeast peptone dextrose; YPP: Yellow pear paste.

\section{Supplementary Information}

The online version contains supplementary material available at https://doi. org/10.1186/s40643-021-00467-2.

Additional file 1: Fig. S1. Metabolic pathways of Z. mobilis. Fig. S2. Original and processed materials used in this study. Fig. S3. Correlation analysis of fermentation results by $Z$. mobilis in pear and persimmon pulp and juice. Fig. S4. Concentration changes during fermentation by S. cerevisiae in Chinese traditional wine (CTW) with the dilution rates.

\section{Acknowledgements}

This paper is dedicated to the memory of Prof. Arnold L. Demain, who passed away on April 3, 2020 at the age of 92 from complications due to Covid19. Prof. Demain was one of the world's leading industrial microbiologists constantly at the forefront of industrial microbiology and biotechnology. He was a wonderful man with a great sense of humor. He was incredibly open and accessible to his students, friends and even people like me who met him a conference. He was always there to provide generous help on everything he could, including providing valuable advice on improving our PNAS manuscript and writing recommendation letters for my personal applications. He also set an example for doing science with passion and dedication. He worked at MIT until the age of 75 and then continued to conduct research and mentor students at the Research Institute for Scientists Emeriti (RISE) at Drew University until May of 2019.

We also acknowledge Mr. Yucheng SUN at WenTianGe Biological Company (Shandong, China) for providing the commercial products of pear pastes and their own product of Chinese traditional medicinal wine and appreciate the assistance of Jessey Yang at University of Pennsylvania for manuscript editing and insightful discussions. 


\section{Authors' contributions}

SY conceived and designed the experiments with inputs from $M M H, X Y C$, $J H, M L$, and JD. MMH and XYC performed the experiments with the help of JH. MMH, XYC and SY wrote the manuscript, and all authors conducted the extensive manuscript review. All authors contributed to data analyses, revised the final manuscript. All authors read and approved the final manuscript.

\section{Funding}

This work was supported by the National Natural Science Foundation of China (CN) (21978071 and U1932141), National Key Research and Development Program of China (2018YFA0900300), Leading Innovative and Entrepreneur Team Introduction Program of Zhejiang Province (2018R01014), the Innovation Base for Introducing Talents of Discipline of Hubei Province (2019BJH021), and Technical Innovation Special Fund of Hubei Province (2019AHB055 and 2018ACA149). We also acknowledge the support from the State Key Laboratory of Biocatalysis and Enzyme Engineering.

\section{Availability of data and materials}

All data generated or analyzed during this study are included in the manuscript.

\section{Declarations}

\section{Ethics approval and consent to participate}

The authors declare that this study does not involve human subjects, human material, and human data.

\section{Consent for publication}

This is our original work and has not been considered in other journals. All authors have agreed to submit this manuscript to Bioresources and Bioprocessing

\section{Competing interests}

The authors declare that they have a patent application associated with this study.

\section{Author details}

${ }^{1}$ State Key Laboratory of Biocatalysis and Enzyme Engineering, Environmental Microbial Technology Center of Hubei Province, and School of Life Sciences, Hubei University, Wuhan 430062, China. ${ }^{2}$ China Biotech Fermentation Industry Association, Beijing 100833, China. ${ }^{3}$ Zhejiang Huakang Pharmaceutical Co. Ltd., Kaihua County, Zhejiang, China.

Received: 19 August 2021 Accepted: 17 November 2021

Published online: 02 December 2021

\section{References}

Apovian C, Gokce N (2012) Obesity and cardiovascular disease. Circulation 125(9):1178-1182

Aziz MG (2011) Production and application of glucose-fructose oxidoreductase for conversion of pineapple juice sugars. Afr J Microbiol Res 5(28):5046-50525

Bantle JP (2009) Dietary fructose and metabolic syndrome and diabetes. J Nutr 9(6):1263S-1268S

Berenguer M, Vegara S, Barrajón E, Saura D, Valero M, Martí N (2016) Physicochemical characterization of pomegranate wines fermented with three different Saccharomyces cerevisiae yeast strains. Food Chem 190:848-855

Brenac L, Baidoo EEK, Keasling JD, Budin I (2019) Distinct functional roles for hopanoid composition in the chemical tolerance of Zymomonas mobilis. Mol Microbiol 112(5):1564-1575

Delli Bovi AP, Di Michele L, Laino G, Vajro P (2017) Obesity and obesity related diseases, sugar consumption and bad oral health: a fatal epidemic mixtures: the pediatric and odontologist point of view. Transl Med UniSa 16:11-16

Demiray E, Karatay SE, Donmez G (2019) Improvement of bioethanol production from pomegranate peels via acidic pretreatment and enzymatic hydrolysis. Environ Sci Pollut Res Int 26(28):29366-29378
Duarte-Delgado D, Narvaez-Cuenca CE, Restrepo-Sanchez LP, Kushalappa A, Mosquera-Vasquez T (2015) Development and validation of a liquid chromatographic method to quantify sucrose, glucose, and fructose in tubers of Solanum tuberosum Group Phureja. J Chromatogr B Analyt Technol Biomed Life Sci 975:18-23

Febbraio MA, Karin M (2021) "Sweet death": Fructose as a metabolic toxin that targets the gut-liver axis. Cell Metab 12:23

Felczak MM, Bowers RM, Woyke T, TerAvest MA (2021) Zymomonas diversity and potential for biofuel production. Biotechnol Biofuels 14(1):112

Günan Yücel H, Aksu Z (2015) Ethanol fermentation characteristics of Pichia stipitis yeast from sugar beet pulp hydrolysate: use of new detoxification methods. Fuel 158:793-799

Hidalgo C, Mateo E, Mas A, Torija MJ (2012) Identification of yeast and acetic acid bacteria isolated from the fermentation and acetification of persimmon (Diospyros kaki). Food Microbiol 30(1):98-104

Hwang KA, Hwang YJ, Hwang IG, Song J, Cho SM (2017) Cholesterol-lowering effect of astringent persimmon fruits (Diospyros kaki Thunb.) extracts. Food Sci Biotechnol 26(1):229-235

Idise O, Odum E (2011) Studies of wine produced from banana (Musa sapientum). Int J Biotechnol Mol Biol Res 2(12):209-214

Jacobson TB, Adamczyk PA, Stevenson DM, Regner M, Ralph J, Reed JL, Amador-Noguez D (2019) ${ }^{2} \mathrm{H}$ and ${ }^{13} \mathrm{C}$ metabolic flux analysis elucidates in vivo thermodynamics of the ED pathway in Zymomonas mobilis. Metab Eng 54:301-316

Johnson RJ, Perez-Pozo SE, Lillo JL, Grases F, Schold JD, Kuwabara M, Sato Y, Hernando AA, Garcia G, Jensen T, Rivard C, Sanchez-Lozada LG, Ronca C, Lanaspa MA (2018) Fructose increases risk for kidney stones: potential role in metabolic syndrome and heat stress. BMC Nephrol 19(1):315

Jonas R, Silveira M (2004) Sorbitol can be produced not only chemically but also biotechnologically. Appl Biochem Biotechnol 118(1-3):321-336

Jones-Burrage SE, Kremer TA, McKinlay JB (2019) Cell aggregation and aerobic respiration are important for Zymomonas mobilis ZM4 Survival in an aerobic minimal medium. Appl Environ Microbiol 85(10):e00193-e219

Kohn JC, Azar J, Seta F, Reinhart-King CA (2017) High-fat, high-sugar dietinduced subendothelial matrix stiffening is mitigated by exercise. Cardiovasc Eng Technol 9(1):84-93

Liu C, Dong H, Zhong J, Ryu DD, Bao J (2010) Sorbitol production using recombinant Zymomonas mobilis strain. J Biotechnol 148(2-3):105-112

Liu Y, Ghosh IN, Martien J, Zhang Y, Amador-Noguez D, Landick R (2020) Regulated redirection of central carbon flux enhances anaerobic production of bioproducts in Zymomonas mobilis. Metab Eng 61:261-274

Loos H, Kramer R, Sahm H, Sprenger GA (1994) Sorbitol promotes growth of Zymomonas mobilis in environments with high concentrations of sugar: evidence for a physiological function of glucose-fructose oxidoreductase in osmoprotection. J Bacteriol 176(24):7688-7693

Martien Jl, Hebert AS, Stevenson DM, Regner MR, Khana DB, Coon JJ, Amador-Noguez D (2019) Systems-level analysis of oxygen exposure in Zymomonas mobilis: implications for isoprenoid production. mSystems 4(1):e00284

Millis N (1956) A study of the cider-sickness Bacillus - a New Variety of Zymomonas anaerobia. J Gen Microbiol 15(3):521-528

Musatti A, Mapelli C, Rollini M, Foschino R, Picozzi C (2018) Can Zymomonas mobilis substitute Saccharomyces cerevisiae in cereal dough leavening? Foods 7(4):61

Nilambari D, Jadhav B (2010) Technology development for ethanol production from the wild fruits of Mimusops Hexandra. Res J Biotechnol 5(3):63-67

Ong WK, Courtney DK, Pan S, Andrade RB, Kiley PJ, Pfleger BF, Reed JL (2020) Model-driven analysis of mutant fitness experiments improves genomescale metabolic models of Zymomonas mobilis ZM4. PLoS Comput Biol 16(8):e1008137

Park S, Baratti J (1991) Comparison of ethanol production by Zymomonas mobilis from sugar beet substrates. Appl Microbiol Biotechnol 1991(35):283-291

Parker C, Peekhaus N, Zhang X, Conway T (1997) Kinetics of sugar transport and phosphorylation influence glucose and fructose cometabolism by Zymomonas mobilis. Appl Environ Microbiol 63(9):3519-3525

Rice T, Zannini E, E, K.A., Coffey, A. (2020) A review of polyols-biotechnological production, food applications, regulation, labeling and health effects. Crit Rev Food Sci Nutr 60(12):2034-2051 
Roda A, Lucini L, Torchio F, Dordoni R, De Faveri DM, Lambri M (2017) Metabolite profiling and volatiles of pineapple wine and vinegar obtained from pineapple waste. Food Chem 229:734-742

Seo JS, Chong H, Park HS, Yoon KO, Jung C, Kim JJ, Hong JH, Kim H, Kim JH, Kil J, Park CJ, Oh HM, Lee JS, Jin SJ, Um HW, Lee HJ, Oh SJ, Kim JY, Kang HL, Lee SY, Lee KJ, Kang HS (2005) The genome sequence of the ethanologenic bacterium Zymomonas mobilis ZM4. Nat Biotechnol 23(1):63-68

Shen W, Zhang J, Geng B, Qiu M, Hu M, Yang Q, Bao W, Xiao Y, Zheng Y, Peng W, Zhang G, Ma L, Yang S (2019) Establishment and application of a CRISPRCas12a assisted genome-editing system in Zymomonas mobilis. Microb Cell Fact 18(1):162

Silbir S, Dagbagli S, Yegin S, Baysal T, Goksungur Y (2014) Levan production by Zymomonas mobilis in batch and continuous fermentation systems. Carbohydr Polym 99:454-461

Silveira M, Jonas R (2002) The biotechnological production of sorbitol. Appl Microbiol Biotechnol 59(4-5):400-408

Stoneman HR, Wrobel RL, Place M, Graham M, Krause DJ, De Chiara M, Liti G, Schacherer J, Landick R, Gasch AP, Sato TK, Hittinger CT (2020) CRISpypop: a web tool for designing CRISPR/Cas9-driven genetic modifications in diverse populations. G3 (bethesda) 10(11):4287-4294

Tastan O, Sozgen G, Baysal T, Kaplan Turkoz B (2019) Production of prebiotic 6-kestose using Zymomonas mobilis levansucrase in carob molasses and its effect on 5-HMF levels during storage. Food Chem 297:124897

Tatli M, Hebert AS, Coon JJ, Amador-Noguez D (2019) Genome wide phosphoproteome analysis of Zymomonas mobilis under anaerobic, aerobic, and $\mathrm{N}_{2}$-fixing conditions. Front Microbiol 10:1986

Taylor SR, Ramsamooj S, Liang RJ, Katti A, Pozovskiy R, Vasan N, Hwang SK, Nahiyaan N, Francoeur NJ, Schatoff EM, Johnson JL, Shah MA, Dannenberg AJ, Sebra RP, Dow LE, Cantley LC, Rhee KY, Goncalves MD (2021) Dietary fructose improves intestinal cell survival and nutrient absorption. Nature 597(7875):263-267

Todhanakasem T, Wu B, Simeon S (2020) Perspectives and new directions for bioprocess optimization using Zymomonas mobilis in the ethanol production. World J Microbiol Biotechnol 36(8):112

Vera JM, Ghosh IN, Zhang Y, Hebert AS, Coon JJ, Landick R (2020) Genomescale transcription-translation mapping reveals features of Zymomonas mobilis transcription units and promoters. mSystems 5(4):e00250

Wang X, He Q, Yang Y, Wang J, Haning K, Hu Y, Wu B, He M, Zhang Y, Bao J, Contreras LM, Yang S (2018) Advances and prospects in metabolic engineering of Zymomonas mobilis. Metab Eng 50:57-73

Xia J, Yang Y, Liu CG, Yang S, Bai FW (2019) Engineering Zymomonas mobilis for robust cellulosic ethanol production. Trends Biotechnol 37(9):960-972

Yang S, Fei Q, Zhang Y, Contreras LM, Utturkar SM, Brown SD, Himmel ME, Zhang M (2016) Zymomonas mobilis as a model system for production of biofuels and biochemicals. Microb Biotechnol 9(6):699-717

Yang H, Sun J, Tian T, Gu H, Li X, Cai G, Lu J (2019) Physicochemical characterization and quality of Dangshan pear wines fermented with different Saccharomyces cerevisiae. J Food Biochem 43(8):e12891

Yang Q, Yang Y, Tang Y, Wang X, Chen Y, Shen W, Zhan Y, Gao J, Wu B, He M, Chen S, Yang S (2020) Development and characterization of acidicpH-tolerant mutants of Zymomonas mobilis through adaptation and next-generation sequencing-based genome resequencing and RNA-Seq. Biotechnol Biofuels 13:144

Yang Y, Geng B, Song H, He Q, He M, Bao J, Bai FW, Yang S (2021) Progress and perspectives on developing Zymomonas mobilis as a chassis cell. Synth Biol J 2(1):59-90

Zheng Y, Han J, Wang B, Hu X, Li R, Shen W, Ma X, Ma L, Yi L, Yang S, Peng W (2019) Characterization and repurposing of the endogenous Type I-F CRISPR-Cas system of Zymomonas mobilis for genome engineering. Nucleic Acids Res 47(21):11461-11475

Zhu JC, Niu YW, Feng T, Liu SJ, Cheng HX, Xu N, Yu HY, Xiao ZB (2014) Evaluation of the formation of volatiles and sensory characteristics of persimmon (Diospyros kaki Lf) fruit wines using different commercial yeast strains of Saccharomyces cerevisiae. Nat Prod Res 28(21):1887-1893
Zou B, Wu J, Yu Y, Xiao G, Xu Y (2017) Evolution of the antioxidant capacity and phenolic contents of persimmon during fermentation. Food Sci Biotechnol 26(3):563-571

\section{Publisher's Note}

Springer Nature remains neutral with regard to jurisdictional claims in published maps and institutional affiliations.

\section{Submit your manuscript to a SpringerOpen ${ }^{\circ}$ journal and benefit from:}

- Convenient online submission

- Rigorous peer review

- Open access: articles freely available online

- High visibility within the field

- Retaining the copyright to your article

Submit your next manuscript at $\boldsymbol{\Delta}$ springeropen.com 